\title{
Author Correction: Heterogeneity-diversity relationships differ between and within trophic levels in temperate forests
}

Lea Heidrich (D), Soyeon Bae, Shaun Levick, Sebastian Seibold (D), Wolfgang Weisser (iD, Peter Krzystek, Paul Magdon, Thomas Nauss (D), Peter Schall D, Alla Serebryanyk, Stephan Wöllauer, Christian Ammer D, Claus Bässler, Inken Doerfler, Markus Fischer, Martin M. Gossner (D), Marco Heurich, Torsten Hothorn, Kirsten Jung (D), Holger Kreft (D), Ernst-Detlef Schulze, Nadja Simons, Simon Thorn and Jörg Müller (D)

Correction to: Nature Ecology \& Evolution https://doi.org/10.1038/s41559-020-1245-Z, published online 13 July 2020.

In the version of this Article originally published, incorrect data curves were displayed in Fig. 2c. The data curves should have appeared as shown below.

This has now been corrected.
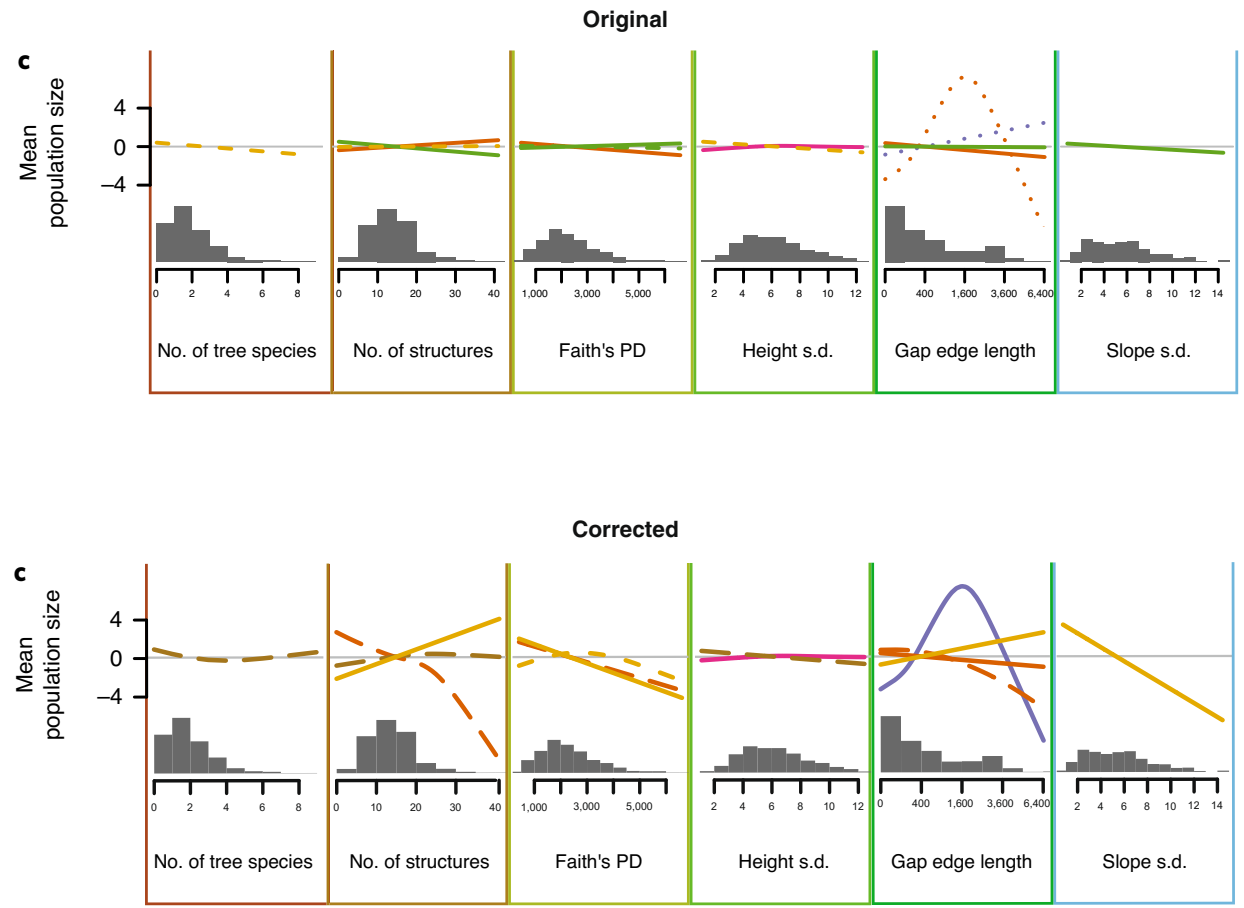

Fig. 2c | Original and Corrected.

Published online: 30 July 2020

https://doi.org/10.1038/s41559-020-01292-0

(C) The Author(s), under exclusive licence to Springer Nature Limited 2020 